\title{
The status of endangered primates in Gunung Halimun Reserve, Indonesia
}

\author{
Karen M. Kool
}

The Gunung Halimun Reserve has the largest area of primary rain forest left on Java. The reserve is important for the habitat it provides for two endangered primates, the moloch Hylobates moloch and the grizzled langur Presbytis comata, which are endemic to western Java. The author presents the results of a survey conducted in the reserve in July 1989 and makes suggestions for further survey work and scientific research on the primates there.

\section{Introduction}

Indonesia, with approximately 29 primate species, has the highest primate diversity in Asia. Twenty of these species have lost more than 50 per cent of their original habitat; of these the moloch Hylobates moloch and the grizzled langur Presbytis comata $=P$. aygula have suffered the greatest loss with only 4 per cent of their original habitats remaining (MacKinnon, 1986a, 1987). The moloch is listed as endangered in the IUCN Red List of Threatened Animals (IUCN, 1986) and both Marsh (1987) and MacKinnon (1986a, 1987) have recommended the inclusion of the grizzled langur on this list. The IUCN/SSC (1987) considered the moloch to merit the highest conservation priority rating (a rating of 10 out of the highest possible rating of 11) and the grizzled langur merited a very high conservation rating (a rating of 9). Marsh (1987) also included these species as among those most in need of status surveys.

The moloch and the grizzled langur are endemic to western Java. More than a third of their remaining habitats lie within reserves (MacKinnon, 1986a, 1986b, 1987). Gunung Halimun (Figure 1) has the largest area of primary rain forest left on Java (MacKinnon, 1986b) and is regarded as the remaining stronghold for these species. The other reserves in western Java, with the exception of Gunung Honje, are either too fragmented or small to support large numbers of these species or are found at altitudes where vegetation is largely unsuitable. For example, there is little primary forest below $1250 \mathrm{~m}$ in the Gunung Gede-Pangrango National Park (UNDP/FAO, 1978) and molochs are rarely found at elevations above $1000 \mathrm{~m}$ (MacKinnon, 1984). Gunung Halimun was allocated a rating of 12 (out of a possible maximum of 13) by the IUCN/SSC (1987) in determining areas of prime importance for reserve development and management projects for Asian primate conservation. Marsh (1987) similarly included this reserve among those considered important for conservation of Asian primates.

In addition to these endangered primate species, the silver langur Trachypithecus auratus sondaicus, which is endemic to western Java, and the long-tailed macaque or crab-eating macaque Macaca fascicularis are found in the Gunung Halimun Reserve.

\section{Survey}

The Gunung Halimun Reserve $\left(106^{\circ} 21^{\prime}-106^{\circ}\right.$ $38^{\prime} \mathrm{E}, 6^{\circ} 37^{\prime}-5^{\circ} 53^{\prime} \mathrm{S}$ ) contains approximately 360 sq $\mathrm{km}$ of continuous primary rain forest within an altitude of 500-1929 m (UNDP/FAO, 1978).

I conducted a survey in the western part of the reserve (Figure 1) in July 1989. Two transects measuring $2.38 \mathrm{~km}$ and $5.4 \mathrm{~km}$ in length were selected within an altitude of $700-1075 \mathrm{~m}$. 
A total of nine censuses was performed along these trails. Primate density was determined from: the area censused $\times$ mean number of groups seen $\times$ average group size, where the area censused $=$ mean perpendicular trail-toprimate distance $\times$ trail length $\times 2$.

The trail census method was compared with the acoustic census method (Kappeler, 1984a) frequently used to determine moloch density. For the latter, the locations of all song bouts heard within three hours after sunrise from a fixed point were plotted on a 1:10,000 scale map. This was repeated on 9 days. The number of moloch groups in the area from which calls were heard was determined and the moloch density estimated.

\section{Moloch density}

The trail census method yielded a mean perpendicular trail-to-primate distance of $55 \mathrm{~m}$ and a density of 2.64 groups per sq $\mathrm{km}$
Table 1. Altitudinal distribution of primary forest in the Gunung Halimun Reserve (adapted from UNDP/FAO, 1978)

\begin{tabular}{lcc}
\hline Altitude $(\mathrm{m})$ & $\%$ of reserve & Area $(\mathrm{sq} \mathrm{km})$ \\
\hline $500-1200$ & 20 & 72 \\
$1200-1400$ & 65 & 234 \\
$1400-1929$ & 15 & 54 \\
Total & & 360 \\
\hline
\end{tabular}

$(\mathrm{SE}= \pm 0.55)$. A density estimate of 2.53 groups per sq $\mathrm{km}$ was obtained from the acoustic census method. Thus, the results from the two methods are similar and a mean value of 2.6 groups per sq $\mathrm{km}$ is used in subsequent calculations of moloch density.

Group size was determined on only three occasions as dense foliage prevented accurate counts at other times. Each of the three groups consisted of four individuals. Kappeler (1984b) reported a mean group size of 3.3 molochs and this value is used in calculations

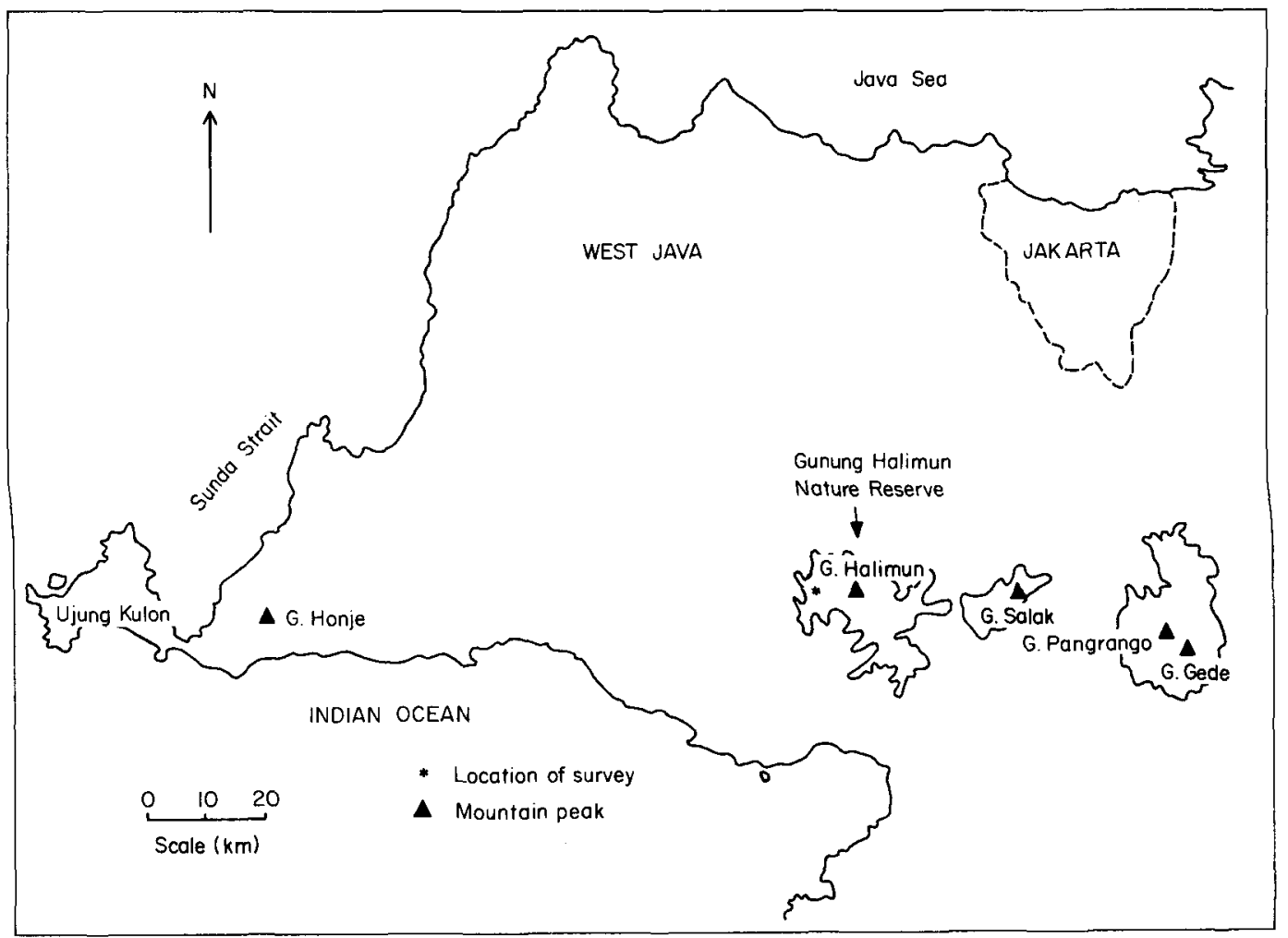

Figure 1. The Gunung Halimun Reserve in West Java, Indonesia. 
PRIMATES OF GUNUNG HAL'IMUN, INDONESIA

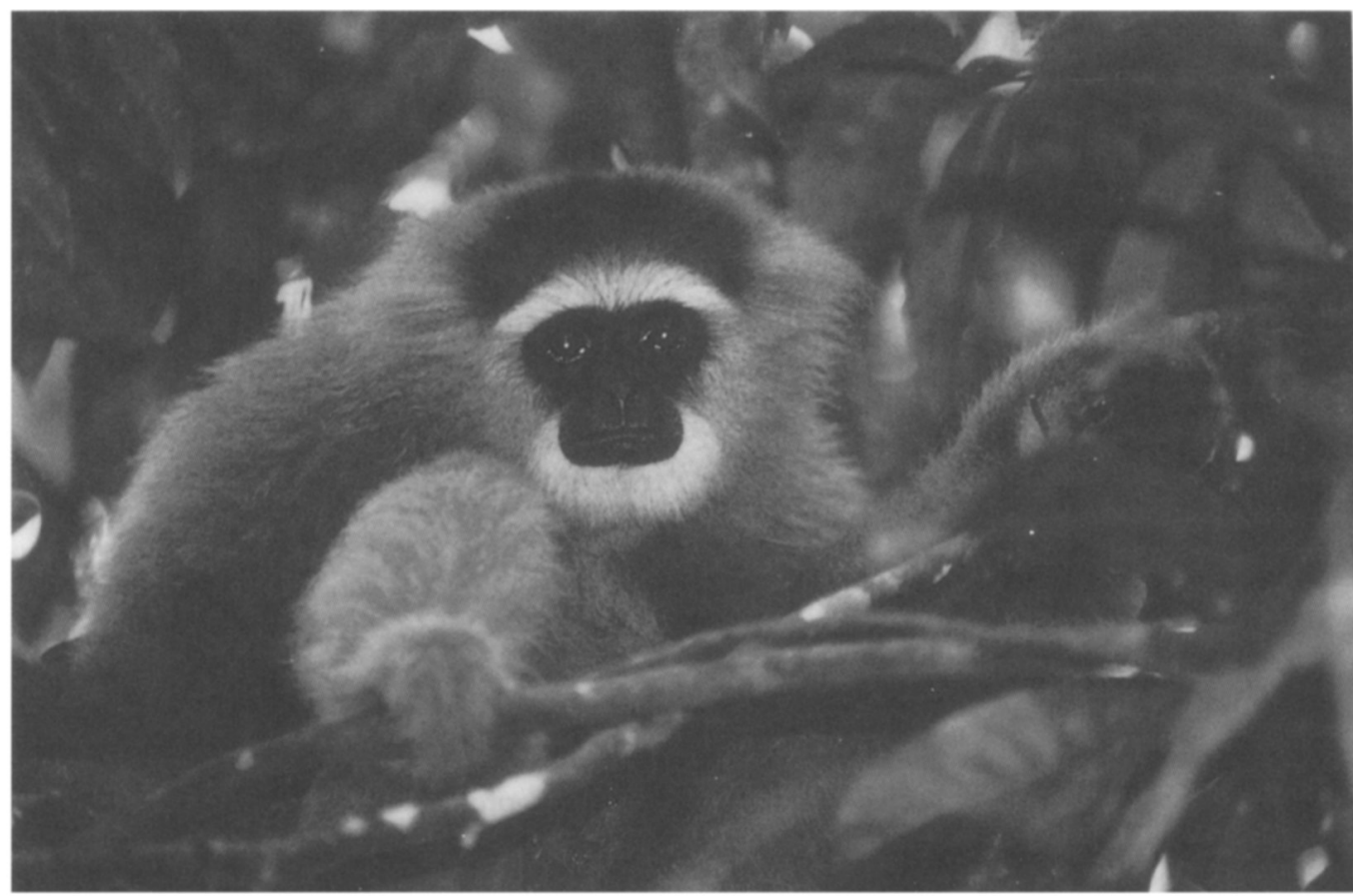

The moloch Hylobates moloch (K. M. Kool).

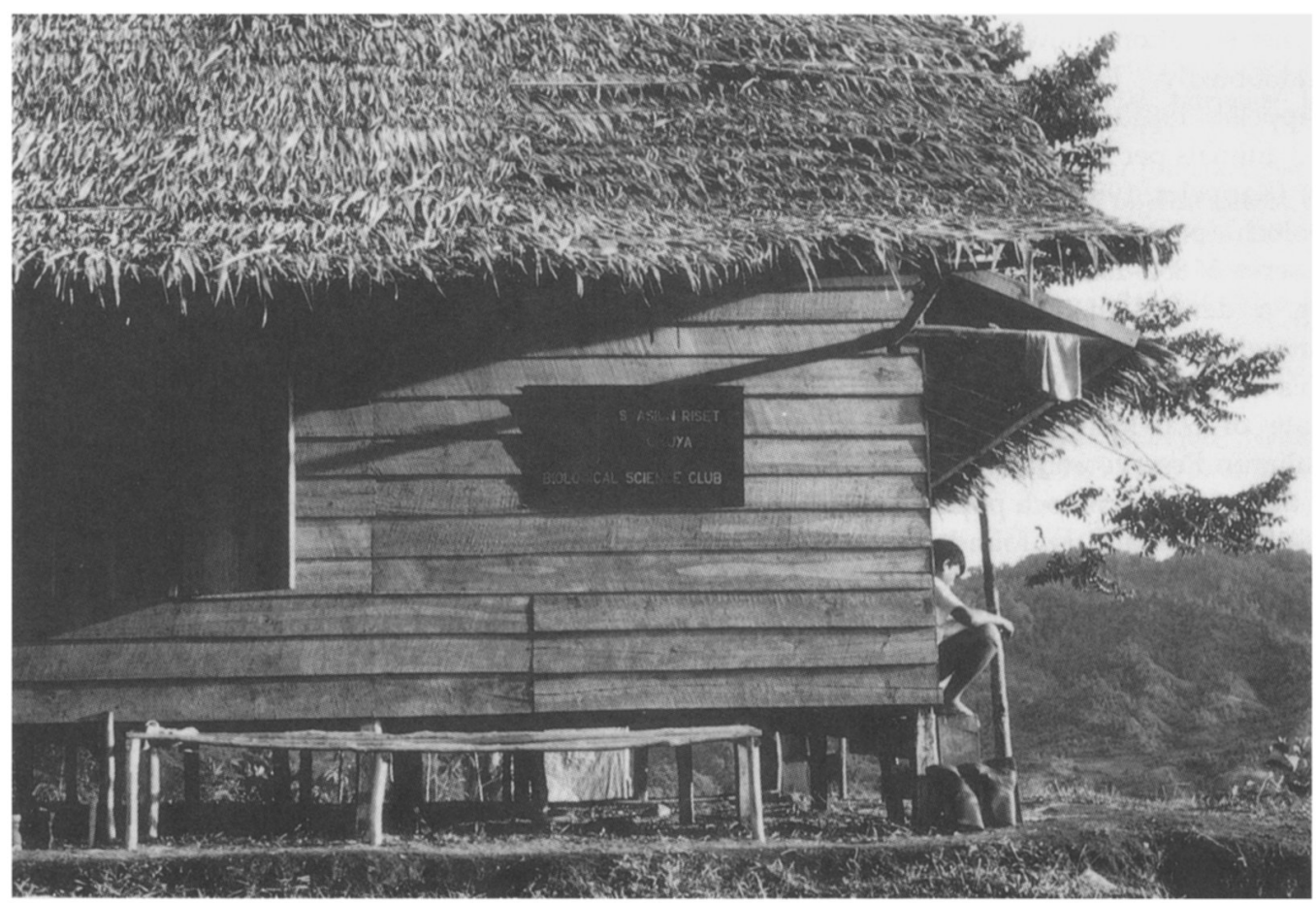

Guesthouse belonging to the Biological Science Club-Jakarta (K. M. Kool). 
of moloch density as it was based on a sample size of 31 groups. Moloch density, within the altitudinal range censused in Gunung Halimun, was determined as 8.6 animals per sq $\mathrm{km}$, being higher than Kappeler's (1984a) estimate of 2-7 molochs per sq $\mathrm{km}$ for hill rain forest (500-1000 m altitude). The latter, however, was derived from a survey of all habitats in which molochs were known or thought to occur, many containing comparatively small forest patches, with only 1-3 censuses having been conducted at each site.

The Gunung Halimun Reserve may be divided into three altitudinal zones (Table 1). Assuming molochs are found at a constant density throughout the $72 \mathrm{sq} \mathrm{km}$ comprising the area within $500-1200 \mathrm{~m}$ altitude, a population of 618 animals is estimated for this hill forest.

Molochs may also occur in the lower montane forest within the $1200-1400 \mathrm{~m}$ altitudinal range, which was not assessed in this survey. Although molochs may occur in forest at an altitude up to $1600 \mathrm{~m}$ (Kappeler, 1984a) molochs have not been recorded above $1350 \mathrm{~m}$ in Gunung Halimun (UNDP/FAO, 1978). At higher elevations, however, moloch density is undoubtedly lower (UNDP/FAO, 1978; Kappeler, 1984a) and has been estimated at 1-3 animals per sq $\mathrm{km}$ for lower montane forest (Kappeler, 1984a). A total estimate for the moloch population in Gunung Halimun Reserve of 852-1320 animals is derived assuming a density of 1-3 animals per sq $\mathrm{km}$ throughout the 1200-1400 m altitudinal zone. This is a refinement of Kappeler's (1984a) estimate of $600-1800$ animals in the Gunung Halimun Reserve and confirmation that most of the protected moloch population, estimated at 1800 animals, is found in this reserve (MacKinnon, 1986a, 1986b). The rest of the total population of some 4824 animals is located in areas where habitats are not protected (MacKinnon, 1986a, 1986b).

\section{Other primates}

The grizzled langur is a very shy animal and was only sighted on two occasions. Therefore, no density estimate was obtained for this species. A previous report (UNDP/FAO, 1978) indicates that the grizzled langur has a very local distribution and may be locally abundant. A group of long-tailed macaques was sighted only once during the survey. This species is generally found in beach vegetation, mangroves and lowland rain forest (MacKinnon, 1986a) and may be uncommon in the reserve (UNDP/FAO, 1978). The silver langur was encountered on four separate occasions while conducting censuses along the trails. Again, this is too few to determine the density of this species but, based on the distance between encounters, the sightings were probably of four separate groups.

\section{Suggestions}

Enhanced protection of the Gunung Halimun Reserve should be encouraged (MacKinnon, 1986a, 1987). With approximately 182 million people in Indonesia, 110 million of whom live on Java, reserves on this island will be placed under increasing pressure by the demands of an increasing human population. Protection of the Gunung Halimun Reserve is vital because this mountainous region provides the watershed on which so many people depend. In addition, this reserve probably contains the largest populations of the endangered moloch and grizzled langur. It is, therefore, essential that remaining areas of hill rain forest (500-1000 m altitude) are carefully managed if the moloch is to remain a viable species in its natural habitat. This altitudinal zone is most threatened and in the east there is currently little forest left below $1100 \mathrm{~m}$.

Scientific research in the Gunung Halimun Reserve would serve as a constant reminder of the reserve's importance and could include the following:

1. Census of molochs at altitudes above 1075 $\mathrm{m}$, to determine reliably the density of this species in the altitudinal zone in which most of the reserve is located.

2. Census of the grizzled langur. This may prove difficult due to the shy nature of this animal but is clearly desirable as only an esti- 
mated 3650 animals of a total population estimate of 8040 are located in protected habitats (MacKinnon, 1986a, 1986b). The proportion of the protected population found in Gunung Halimun is unknown but most may be located here (MacKinnon, 1987).

3. Ecological and behavioural studies of the moloch and the grizzled langur (for previous work on these species refer to Kappeler (1984c) and Ruhiyat (1983), respectively).

4. Comparative studies of all four primate species that occur in sympatry in this reserve. The silver langur with a total population estimated at fewer than 10,000 animals (MacKinnon, 1987) would clearly benefit from such research. Although several aspects of the behavioural ecology of this species have been studied (Kool, 1989), the diet of this Trachypithecus species has not been studied in a location where it occurs in sympatry with a Presbytis langur.

\section{Acknowledgments}

I would like to thank Mr Bekti Siswarto (Biological Science Club-Jakarta) and Ms Kim Plummer for assistance in the field. I also wish to thank the Biological Science Club-Jakarta for allowing us to stay in the Club's House on the border of the Gunung Halimun Reserve and to acknowledge the club's research efforts in the reserve. Support for this work was provided by grants to the author from the University of Sydney, the Australian Geographic Society and Garuda Airways. Dr David Croft kindly commented on a draft of this paper.

\section{References}

IUCN Conservation Monitoring Centre Cambridge UK 1986. IUCN Red List of Threatened Animals. IUCN, Gland, Switzerland and Cambridge, UK.

IUCN/SSC Primate Specialist Group. 1987. Action Plan for Asian Primate Conservation: 1987-91. (Compiled by A. A. Eudey). UNEP, IUCN, WWF, Washington DC.

Kappeler, M. 1984a. The gibbon in Java. In The lesser Apes: Evolutionary and Behavioural Biology (eds $\mathrm{H}$. Preuschoft, D. J. Chivers, W. Y. Brockelman and N. Creel), pp. 19-31. Edinburgh University Press, Edinburgh.
Kappeler, M. 1984b. Vocal bouts and territorial maintenance in the moloch gibbon. In The Lesser Apes: Evolutionary and Behavioural Biology (eds $\mathrm{H}$. Preuschoft, D. I. Chivers, W. Y. Brockelman and N. Creel), pp. 376-389. Edinburgh University Press, Edinburgh.

Kappeler, M. 1984c. Diet and feeding behaviour of the moloch gibbon. In The Lesser Apes: Evolutionary and Behavioural Biology (eds $\mathrm{H}$. Preuschoft, D. J. Chivers, W. Y. Brockelman and N. Creel), pp. 228-241. Edinburgh University Press, Edinburgh.

Kool, K.M. 1989. Behavioural ecology of the silver leaf monkey, Trachypithecus auratus sondaicus, in the Pangandaran Nature Reserve, West Java, Indonesia. PhD Thesis, The University of New South Wales.

Mackinnon, J.R. 1984. The distribution and status of gibbons in Indonesia. In The Lesser Apes: Evolutionary and Behavioural Biology (eds $\mathrm{H}$. Preuschoft, D. J. Chivers, W. Y. Brockelman and N. Creel), pp. 16-18. Edinburgh University Press, Edinburgh.

MacKinnon, K. 1986a. The conservation status of nonhuman primates in Indonesia. In Primates-The Road to Self-Sustaining Populations (ed K. Benirschke), pp. 99-126. Springer Verlag, New York.

MacKinnon, K. 1986b. The conservation status of Indonesian primates. Primate Eye, 29 (Suppl.), 30-35.

MacKinnon, K. 1987. Conservation status of primates in Malesia with special reference to Indonesia. Primate Conserv. 8, 175-183.

Marsh, C.W. 1987. A framework for primate conservation priorities in Asian moist tropical forests. In Primate Conservation in the Tropical Rain ForestMonographs in Primatology (eds C. W. Marsh and R. A. Mittermeier), Vol. 9 pp. 343-354. Alan R. Liss, Inc., New York.

Ruhiyat, Y. 1983. Socio-ecological study of Presbytis aygula in West Java. Primates, 24, 344-359.

UNDP/FAO. 1978. Proposed Halimun Nature Reserve Management Plan 1979-1982. Field Report of UNDP/FAO Nature Conservation and Wildlife Management Project INS/73/013 (based on the work of Jan Wind and Bambang Karyo Soesilo).

Karen M. Kool, School of Biological Sciences, The University of Sydney, Sydney, NSW, 2006, Australia. (Current address: School of Biological Science, The University of New South Wales, PO Box 1, Kensington, NSW, 2033, Australia.) 